\title{
Unsägliches ansagen
}

\author{
oder warum man es beim Predigen nicht recht \\ machen kann
}

Ralph Kunz

Wilfried Engemann vertritt in einem homiletischen Essay die provokative These, dass eine wirksame Predigt schöpferisch zu sein hat. Das ist ein steiler Anspruch - gleichsam "senkrecht nach oben". Denn Engemann meint tatsächlich nicht das Kreative, sondern das Kreatorische. Man müsste wie Gott reden können, damit das Evangelium "senkrecht von oben" auch wahrhaftig unten aufschlägt.

Mit dem Anspruch kommt der Einspruch. Wie soll denn das gehen? Kann eine Rede Heil spenden? Ist es möglich, dass menschliche Worte Leben schaffen und Tote auferwecken können? Natürlich ist die gezielte, hart an der Grenze der Blasphemie stehende Provokation bei näherem Hinsehen eine Euphemie. Ein Eingangsbeispiel - wenn man so will, der didaktische Pass zur homiletischen Reflexion macht deutlich, dass Engemann den Ball etwas flacher spielt, als es auf den ersten Blick scheint. Es wird auf eine studentische Predigt verwiesen, in der die Rechtfertigungslehre abgehandelt wird. Die kritische Rückfrage an die Predigt zielt darauf, das Verhältnis von Lehre, Rechtfertigung und gottesdienstlicher Rede zu klären. Ein Gottesdienst ist keine Seminarsitzung und die Predigt keine Vorlesung. Vor allem aber ist Rechtfertigung ein Geschehen und keine Lehre. Und weil es ein Wortgeschehen ist, das sich an und in einer Person ereignet, wird Gottes rechtfertigendes Handeln als Anrede in die Tat umgesetzt. Wenn nicht so, wie denn sonst? Wenn nicht durch berufene Zeugen, durch wen oder was denn sonst? Denn es hat Gott gefallen, sich durch den Mund seiner Zeugen zu offenbaren.

Die aporetische Forderung der schöpferischen Rede will also paradoxerweise - das Ereignis des Wortgeschehens davor retten, zum Ergebnis des rhetorischen Geschicks der Predigerin zu werden. Aber man müsste ja keine Homiletik treiben, wenn es nur darum ginge. Wenn auch die Rechtfertigung keine Lehre ist, hat eine Rechtfertigungslehre dennoch ihr Recht. So ist auch die Predigt keine Lehre und will doch gelernt sein. Schliesslich kann, wer sein Mundwerk nicht beherrscht, einiges falsch machen. Man kann z.B. seine Hörer verlieren und sich in Höhen hineinreden, zu denen niemand mehr aufsteigen mag. 
Klar, man soll es nicht allen recht machen, aber sich um eine Form der Rede bemühen, die der Verkündigung angemessen ist. Das ist gewissermassen ein ceterum censeo der evangelischen Predigtlehre. So manövriert sich die theologisch begründete (und verkündigte) Praxistheorie freilich nur weiter hinein in das Paradox. Denn Predigen heisst evangelisch verstanden, mit dem Anspruch zu reden, dass Gottes Einspruch hörbar wird. Kein Mensch kann Gott zur Rede stellen, aber jede Predigerin muss sich der Herausforderung stellen, dass er zu Wort kommen kann. Und wenn man mit dieser Vorgabe nicht an Ort treten will, muss man doch sagen, wie man's richtig macht. Engemanns Argumentationsgang reiht sich in diesen Strang der Theoriegeschichte ein und vertritt so gesehen eineVorwärtsstrategie.

Nun haben diese und andere Vorwärtsstrategien zweifellos ihre Berechtigung. $\mathrm{Ob}$ wir es pneumatologisch, christologisch oder schöpfungstheologisch begründen: wir kommen an den Punkt, an dem wir zugeben, dass eine Predigt etwas unsäglich Freudvolles ansagt. Was die Rechtfertigungslehre mit ihren Unterscheidungen Gesetz und Evangelium wie Glaube und Werk als Regeln formuliert, ist aber noch keine Ansage, die Annahme, Vergebung und Versöhnung geschehen lässt.

Wenn es eine Vorwärtsstrategie gibt, muss es auch eine Rückwärtsstrategie geben. Worin besteht sie? Darin, dass man sich nicht auf die Äste der Sprachfindung hinauslässt, sondern zum Stamm und von da zu den Wurzeln zurückfragt, woher das Wort kommt, das schöpferisch oder erlösend oder befreiend wirkt. In dieser Bewegung zum Ursprung ist darum weniger die poetische, als die pathische Fähigkeit einer Predigerin gefragt. Kann sie der Lust entsagen, alles sagen zu wollen? Hören die Angeredeten, dass einer redet, der auf das Wort Gottes lauscht? Wird im Gesagten das Unerhörte des Evangeliums vernehmbar?

Die Rechtfertigung des Sünders ist keine Aufgabe, die sich der Redner, der predigt, für diesen oder jenen Sonntag vornehmen kann, um am anderen Sonntag entsprechend heftig mit den Gesetzestafeln vom Sinai hinunter zu poltern. Wenn Rechtfertigung der Artikel stantis et cadentis ecclesiae ist, steht und fällt mit der rechtfertigenden Rede die Predigt. Was wiederum zum schon bekannten Paradox zurückführt, dass nur Gott selbst dieses Wort im Herzen der Gläubigen sprechen kann. Aber es ist doch ein Fortschritt, wenn die Rechtfertigungslehre zur Einsicht verhilft, dass die Rückkehr zum Wort der anfänglichen Gnade als ein Geschehen anzusehen ist, das Prediger und Hörer angeht. Bekehrt wird auch der grosse Theologe, der wortgewaltige Prophet oder die feinfühlige Poetin. Sie alle, die 
es Gott recht machen, weil sie wissen, wie man reden kann, dass es einem so richtig unter die Haut geht. Oder auf die Nerven.

Der Umgang mit dem Unsäglichen liesse sich wie jeder Umgang in eine Lehre überführen und methodisch reformulieren. Möglich wäre es, die Homiletik mit der Forderung nach einer spirituellen Haltung zu verbinden. Man hätte dann die Lehre daraus gezogen, in welcher Einstellung man Gottes Wort der Rechtfertigung ansagt. Wer so ans Werk geht, hat den Einspruch gehört und wird dem Anspruch einer evangelischen Homiletik gerecht. Kann man es beim Predigen doch recht machen?

So könnte man es sich zurechtlegen und würde dann aber den kritischen Impuls einer Predigtlehre, die keine Lehre sein will, neutralisieren. Das Wunder lässt sich methodisch nicht fixieren. Abgesehen davon, dass man noch nicht dichten kann, wenn man eine Poetologie gelesen hat. Nein, man soll es nicht recht machen wollen.

Damit ist noch einmal die Pointe einer rechtfertigungsinspirierten Predigtlehre herausgestellt. Der Glaube, den der geistliche Redner wecken möchte, ist weder die Frucht seiner künstlerischen noch seiner moralischen oder intellektuellen Leistung. Der Glaube ist niemals das Produkt einer irgendwie motivierten Werkgerechtigkeit. Er wächst auch nicht (schneller) im feuchtwarmen Klima religiöser Annäherungsversuche und entzündet sich nicht im Funkenregen einer feurigen Höllenpredigt. Was immer da wächst oder schrumpft oder brennt: es ist nicht Glaube. Jeder Versuch, das Wunder der Rechtfertigung mit der vorgefertigten Predigt zusammenzuschliessen, raubt der Rede, die diesem Wunder dient, ihre Dynamik. Vielleicht ist das gar nicht so steil.Vielleicht ist es einfach quer zu dem, was wir gewohnt sind.

- Ralph Kunz ist ordentlicher Professor für Praktische Theologie mit den Schwerpunkten Homiletik, Liturgik und Poimenik an der Universität Zürich. 